\title{
Improving Performances in the Public Sector: The Scientific Management Theory of F W Taylor and Its Implications for Library and Information Services
}

\author{
BY \\ ABDULLAHI MUSA IBRAHIM \\ Department of Library and Information Science, Ahmadu Bello University Zaria, \\ Nigeria
}

\begin{abstract}
The need for improve performances in organization has always been a source of concern for management in both the public and the private sector. This paper sought to discuss the principle of scientific management theory as propounded by F.W. Taylor with the aim of ensuring that public services organizations adopts the principles for enhanced productivity, efficiency and the attainment of organizational objectives.
\end{abstract}

The paper highlighted the principles of scientific management theory, and it explores how public service sector, notably the Library and Information Science segment in Nigeria, can benefit from its well tested principles. The main reason for the paper is the apparent inefficiency of the public sector, as observed and reported by several scholars over time.

\section{Introduction}

Gardner, 1984 observed that, "in libraries we often think of our roles as checking out books and answering reference questions. Yet we have a cathedral of knowledge in our institution. We need to orient our services to unlock that knowledge for patrons. This gives us real challenge, a challenge that requires highest level of performance, excellence and renewal". The above quotation is not the only one urging libraries to fine tune the way they do things to achieve high performances. Trying to achieve high performance has been an issue that is of utmost importance in organizations. It is a subject that has drawn a lot of attention in every type of library and information centre.

But achieving high productivity depends on how effective the management of libraries is. John (1967) has observed that, management is the way employees are managed in order to facilitate the accomplishment of organizational objectives, so as to secure the best satisfaction to both the employer and the employee. The role of management therefore, since the emergence of Scientific Management, involves ensuring that improved performances are achieved. To buttress the importance of management in achieving high productivity, Kimball, Dexter S. (1971) observed that, there is no guarantee that a well-organized enterprise with modern equipment and organized personnel shall always be able to deliver the desired improved performances without an able administrator who can manage well.

Achieving improved performances in organizations therefore depends upon an efficient administrator, who can ensure that the efforts of employees are channeled in the right direction toward the desired objectives. With so much inefficiency in the Nigeria public sector achieving performance improvement lies in the adoption of systematic management, rather than searching for unusual or extraordinary staff or employees. This by far, is what F. W. Taylor practiced years ago; that enable him to achieve astonishing and dramatic improvements in performances across organizations. F W Taylor was the first person to bring improved performances in organizations through a clear laid down philosophy, which he called the scientific Management principles (SM). According to Taylor, Stephen Knouse, and Kerry D. Carson 1993 they observed that, the fundamental principles of the scientific management theory are applicable to all kinds of human activities. It can be applied to the management of homes; farms; churches, philanthropic institutions, universities, and governmental departments. Because of the efficacy of the principles, it spread rapidly throughout organizations and are used in different setting in the contemporary world.

Library and Information service environment in Nigeria require improved performance in their operations. This is because libraries today are faced with radically changing user demands. However it seems that, catching up with improved performances has been very elusive for the Library and Information Science (LIS) environment. This can be seen from dozens of researches conducted by both undergraduates and postgraduates scholars in Nigeria. The conclusion of one research after another proved to be the same; that the services provided by libraries are below standard, Umar 1985:78; Oladipo 
1990:8; Oyeleke 1998:68 ; Oyedum 1992:73; Mohammed 2001:116.

Therefore in order to achieve improved performance in libraries, there is the need to find solution to the problem of inefficiency and lack of productivity. This by far is not easy, as Martell (1989) noted that, there may be some variation in perspective about the ways to achieve high performances in libraries and the practical responses that need to be undertaken. This paper therefore is of the opinion that, adopting a systematic, theory-based management style is one solution that can yield the greatest results fastest. Accordingly it has been opined in this paper that, since the conditions that gave birth to SM theory years ago, are invariably present today in Nigeria within the library and information science circle; the library sector should adopt scientific management theory (SM) for it to achieve improve performances.

\section{Performances Improvement}

Performance improvement is an issue that is of relevance to the library and information science field. It is of strategic importance to the information profession. Thomas (1996) has observed that, the goal of improving services remains an integral part of the LIS professional ethos. Therefore libraries and other public institutions should continuously strive to improve their services, in the same way corporate organization does; by setting up performance benchmark that are visible, quantifiable, and time bound, and which they are committed to, in order to meet up to the expectations of their clients.

But achieving improved performance in organizations requires that services be evaluated for quality, to determine how effective the services are. Dong-Suk Kim observed that, evaluating efficiency of services in libraries and information centers is not just the question of providing users with new services; it also focuses on the degree of utilization of such services by users, and their satisfaction in terms of quality and quantity. He further added that, evaluating service quality in library must focus on the user and that is why some libraries now evaluate their services using model of service quality evaluation found in the marketing field.

Achieving high performance according to Martell (1989) does not only mean that staff should be working harder, but it means staff to be working smarter and better. Therefore library managers need to discover new path to make their staff work harder and smarter. High performance is an important issue in many organization including libraries. Martell
(1989) observed that, performance relates not so much to efficiency or how fast employees performed a job, but to the effectiveness or the degree to which the work performed allows the organization to achieve its goals.

According to Rosemary DuMont (1980) librarians have had difficulty defining organizational effectiveness because they have not been able define library goals in a satisfactory manner. Therefore for high performance to be achieved in libraries, library managers and staff need to develop performance benchmark similar to the one found in sport. According to Martel (1989) measuring attainment or progress towards goal is an important characteristic of sports. Sports figure know when they have done something well: they win or lose. Therefore for high performance to be achieved, the management of libraries must ensure that the job of employee is scheduled so that the organization knows exactly what each employee does daily. The daily work of employee must contribute to the objectives of the library. This is because achieving high productivity in organizations as observed by Akin and David (1986) is achieved through making employees to do what no one else thinks is possible.

\section{Scientific Management Theory (SM)}

Frederick Winslow Taylor propounded the scientific management theory, which emphasized on job efficiencies, by searching for the 'one best way' to do every job. Taylor developed an array of principles to enhance improved productivity in organizations, as well as created a mental revolution between workers and employers. Some of the principles he developed includes various wage and bonus incentive plans, techniques for measuring work input and output, and an ideology of authority in organization. $\mathrm{He}$ developed ways of increasing productivity by making work easier to perform and methods for motivating the workers to take advantage of the new management devices. Taylor recognized that scientific management would require a complete mental revolution on the part of both management and workers. On the part of management the scientific approach required the following Principles.

- Develop a science for each operation to replace opinion and rule-of-thumb.

- Determine accurately from the science the correct time and method for each job.

- Set up a suitable organization to take all responsibilities from the workers except that of actual job performance.

- Select and train the workers scientifically 
- Be governed by the science developed for each operation and cooperates with workers.

There are various studies conducted under the scientific management principles and these are:-

SHOVEL WEIGHT STUDY: This study was mainly to determine the standard working tool that will make work easier. Initially each man had a shovel used in shifting coal and handled about 25 tons of material as day. The shovel was then made smaller for each man, and the daily tonnage rose to 30 . From this study, Taylor was able to decide an ideal shovel size for each work man to perform better.

TIME \& MOTION STUDY: This was designed to know the time and the movement of worker from one place to another as ore or coal being shifted. The workers were timed and movement watched closely to avoid unnecessary delay when shoveling, which also increase productivity in organizations.

PIECE RATE STUDY: The study was a kind of incentive system aimed at increasing job performance. Workers who show themselves capable of achieving high output at a given time were rewarded with wages increased. Those who could not meet the standard received low rate of wages and were given special training on how to attain standard.

MANAGEMENT STANDARD STUDY: Each worker was given a specified task with instructions and time limit to perform. Job was segregate and divided among workers. Responsibilities were shared according to capabilities and experiences. Planning of duties is determined through the cost expended and flow of work.

\section{The Merits of Scientific Management Theory}

SM is aimed at stretching and getting every employee to perform his best and to put all his efforts and attention towards achieving the goals of the organization. Any employee, who fails to achieve the goals and objectives set forth by the organization daily, will get a pay that commensurate with his performance. SM is also aimed at finding solutions to the problems of under-working by employees. Under working is defined as, deliberately working slowly so as to avoid doing a full day's work, this by far is the greatest evil by employees to their organization. SM therefore is targeted at removing one of the fundamental causes for dull times in organizations. When dull time is eliminated productivity, efficiency, and profitability will increase. This will in turn bring higher wages for employees and more revenue to the organizations.

Cole (2004) listed the following points as the benefits arising from Scientific Management Theory:

- Its rational approach to the organization of work enabled tasks and process to be measured with a considerable degree of accuracy.

- Measurement of tasks and processes provided useful information on which to base improvements in working methods. And by improving working methods, it brought enormous increases in productivity.

- It enabled employees to be paid by results which reduces dull time

- It stimulated managements into adopting a more positive role in leadership.

- It contributed to major improvements in physical working conditions for employees as everything that is needed to make the job done would be provided

- It provided the foundations on which modern work study and other quantitative techniques could be soundly based.

Hamel (2002), a modern management theoretician observed that, most of the modern techniques of management of today have their roots from the SM. He referred to the concept of "re-engineering" that is practiced widely today in organizations as nothing new, but as the, '21st century SM.

Also the "best way" of undertaking a task in organization was pioneered by the SM. It is worthy to note that up till today, modern management practitioners are still interested in finding the best possible ways of accomplishing a job with minimal efforts, and the system is today referred to as "benchmarking".

SM theory also pioneered the breaking of every task in organizations into constituent elements. This system is still practiced today and it is referred to as business process re-design.

$\mathrm{SM}$ is concerned with getting rid of things that don't add value to the workings of the organization. This management technique is also used today and it is referred to as "work out" in modern organizations. Also the continuous quality improvement process was originated by Taylor, and is still practiced today in organizations. 


\section{Implementing Scientific Management Principles for improved performance in Library and Information Service Environments in Nigeria}

In adopting scientific management principles to increase productivity and efficiency in library setting, the management of libraries must work according to scientific laws, and specific procedure. This entails making every activity in the library to be preceded by preparatory acts of management. This means that, every employee should be taught what is required of him in terms of objectives and target to be achieved. The employee should be assisted by supervisors; and under no circumstances should the worker be coerced by supervisors, or be left alone on his own without management support. When staff are thought exactly what is required of them, and receive management support, they are likely to can perform their work better and faster, thereby increasing efficiency and improvement in performances.

Scientific management involves goals and objectives settings, which are necessary for improving performances. In Nigeria, this may require the need to have a total reorientation in the Nigeria library scene. A total reorientation is needed, where by every library institution must have identifiable goals and objectives every year. The goals and objectives should be broken down into quarterly and monthly objectives that are quantifiable, measurable, and achievable, with time has time frame within which it must be accomplished. Also each department or unit of the library should have its own objectives that are drawn from the general objectives of the library. Employees should therefore draw their daily objectives from their divisional or units objectives.

As soon as individual objectives are developed, action plan would then be drawn, where by each objective will be stated and the resources required to accomplish each objectives, the time frame upon which each activity must be accomplished, and the person that is responsible for accomplishing the task. When this is done every individual employee in the library, will know exactly what is expected of him. Every employee would understand how his job can contribute to the achievement of the wider organizational objectives and goals. Every employee can quantify his value to the organization. Every employee should know how his performance will either negatively or positively affect the overall performance of the organization. And also, every employee should easily determine on hourly basis and in quantitative terms what the organization will gain if he puts his best effort on the job and vice versa.

Application of SM methods yield significant improvements in productivity. For example, Taylor's shovel work study at Bethlehem Steel Works has succeeded in reducing fatigue and increasing employee productivity. Library managers can adopt the same principle which can cut down the movement of staff during book shelving, or going to and forth in attending to library users, or in the cataloguing department. When employees are less fatigued, they conserve more energy and time; which help in increasing productivity.

Taylor's wage incentive systems, (the piece rate) can be used in the Nigeria library setting to recruit hourly workers, notably students in the university library to do professional and Para-professional jobs. Wage system, based on hourly rate, can be adopted by Nigeria library systems to provide better and improved services in the academic library. Such services can be quantified on hourly basis. For example, if the management of the library determines that it takes an average of 15 minutes to catalogue a book, then it can with degree of certainty say that, 4 books would be catalogued in one hour. Therefore if a wage earner is employed to work for three hours, it is expected that 12 books would be catalogued. Thus, when the wage earner goes beyond 12 books, he should be given a bonus. If he performs below the target, he should receive less pay. This system will increase productivity by eliminating redundancy, idle time, and under capacity utilization of staff.

The Scientific Management theory also focuses its attention on improving productivity through careful study of the worker, the task, and the work place. It systematically analyzes human behavior at work, break down each task into its smallest unit and figure out the best way to do each job. The aim is to ensure that employers and employee work for greater efficiency and productivity which will result in higher wages for employees and higher turnover and profitability for the organization. This also can be applied in the library and information science settings. It can be done by periodically studying the employees and every library task. The management should then ensure that every staff receives the necessary training to enable him perform the specific task he is assigned to perform. For example, if an employee is in charge of manning the front desk of the library, for all practical purposes, and for the job to be accomplished well, he must, as a matter of necessity, be given the necessary training on customer services. He should also be given the 
necessary training on, how to identify different customer categories, how to handle different customers, how to respond to queries, and so on. The employee will also need to have the necessary tools to enable him undertake the job well. Accordingly, the front desk staff, would for instance, require a link between him, and the various units in the library through intercom services. He may also require a well decorated office that will serve as the front desk office, which will help to build confidence on the front desk staff.

The SM theory also emphasizes on, "studying the work place". This is useful, as it will provide the management of libraries with information that is necessary to make the work place conducive for employees to perform any given task. Accordingly, the work environments of workers in the technical section of the library, would be different from the work environments of workers at the circulation unit or the reference section of the library. The library must therefore take cognizance of the peculiarity of each unit, and devise an effective work environment that will suit a given task for effective productivity. Uniform working environments alone in a library may not provide staff with the necessary motivation to perform well beyond their capacity. This practice should be avoided in libraries in Nigeria.

Scientific Management Theory also aimed at transforming organizations by redefining what had hitherto has been production problems, as management problems. The library and Information service institutions can use this approach, to solve the perpetual problems of library services. Most of the problems of librarianship are purely managerial and behavioral in nature. The problems of library and information science environment are beyond the technical aspect of the profession. It is unfortunate however that, Library and Information science field has no ready answers to the questions on how inefficiency in the provision of library service could be rectified. This is because the whole body of knowledge in librarianship is embodied in technical aspects of information provision, with little or no body of knowledge to support solving behavioral and managerial issues. Therefore, rather than focusing on cataloguing, classification, reference services as problems, focus should be more on behavioral issues of information provision, like customer focus approach, publicity and marketing, communication, motivation of employees, supply chain management, creating market niche, organizational culture and its effects on service provision, system thinking, team building, and other management and behavioral concerns. When this is done, result oriented outcomes would be achieved in the most efficient manner possible, which will see library services becoming efficient, orderly, useful and responsive to the needs of the community.

\section{The Way Forward:}

It is therefore suggested that, libraries should follow the tradition of SM, which has as one of its ideals, a waste-free system, with high productive outcome that is perfected by human efficiency through the application of science in the management of organizations. There is a great deal of certainty that, the problems of inefficiency which is a characteristic of library and information science field in Nigeria, could be surmounted through the use, and the application of the principle of scientific management. Through the application of SM, it is possible to eliminate waste and "confusion" that is inherent in library services provision in Nigeria.

This viewpoint can well be illustrated by the case of Library and information services in a university setting. The main mission of academic library is to accelerate research output by lecturers and scholars. But the key issue remains that, there may be no procedure in academic libraries that will ensure the achievement of these cardinal objectives in quantifiable terms. For quite a long time, university libraries in Nigeria provide services to the academic community under the assumption that it supports teaching, research, and scholarly pursuits. There is the need for them to have a scientific approach to relating the mission and the objectives of the library to the research output of scholars or the success or failure of students at any given period in time in the history of library services in Nigeria. That is to say, important issues like, determining the total numbers of scholars, total numbers of lecturers, and the total number of students in relation to library staff and the proposed services to be provided is should be considered. What is also needed is the knowledge of the average research output expected by each category of university lecturer, students, and scholars per academic session, and how the library can help towards achieving the research objectives in quantifiable terms. The knowledge of SM can help to address these concerns.

\section{Conclusion}

It is inferred that libraries should adopt Scientific Management Theory in order to achieve the so much needed improvement in services. When libraries adopt the Scientific Management principles, it is opined that, there would, be some significant changes in the practice of library services in the years to 
come. Thus but, as long as there are problems of under capacity utilization of staff in the delivery of library services, there will be a need for systematic and organized application of scientific management principles in our libraries.

\section{References}

DuMont R. R (1980) A conceptual basis for library effectiveness College and research libraries 41(march) 103-111

Gardner J. W. 1984 Excellence: can we be equal and excellent too? Rev ed Newyork N.W. Norton

John Gaus M,(1967) 'A theory of organization in public administration, In' The frontiers of public administration, by John M. Gaus, Leonard D. W and Marshall E. Dimock. New York : Russel \& Russel, 1967. p-66-7

John M Library organization management, 'A theory of organization in public administration, www.infosciencetoday.org/organization1.htm

Kimball, Dexter S. and Kimball, Dexter S. (1971) Principles of industrial organization- New York : McGraw-Hill, 1947 ( 4th Indian repr. 1971 ).p. 158 .

Mohammed H T (2001) Use of indexes and Abstract in Special Libraries in Kaduna and Zaria Metropolis A thesis submitted to the Postgraduate School Ahmadu Bello University Zaria in partial fulfillment of the requirement for the degree of Master of Library Science

Martel C Achieving High performance in library work library Trends Vol. 38(1) summer 1989

Oyedum G. U. (1992) Utilization of Library Resources and Services by the staff and students of the Federal University of technology, Minna. A thesis submitted to the Postgraduate School Ahmadu Bello University Zaria in partial fulfillment of the requirement for the degree of Master of Library Science

Oladipo G. J.(1990) Evaluation of user Education Program of Kaduna Polytechnic Library Complex. A thesis ssubmitted to the Postgraduate School Ahmadu Bello University Zaria in partial fulfillment of the requirement for the degree of Master of Library Science
Oyeleke A. P. (1998) Information needs of metallurgies and Information Services provided by Libraries o Metal Industries in Nigeria. A thesis submitted to the Postgraduate School Ahmadu Bello University Zaria in partial fulfillment of the requirement for the degree of Master of Library Science

Stephen B. Knouse; Kerry D. Carson A Comparism management philosophies of two leaders Edward Deaming and Frederick Winslow Taylor International Journal of Public Administration, Volume 16, Issue 101993 pages 1621 - 1658

Taylor F W The Principles of Scientific

Management. (1911)

www.eldritchpress.org/fwt/t1.html

Thomas W. S. Perspective on Quality in Libraries. Library Trend Winter 1996 Vol. 44 (3)

Umar H. (1985) Library services at the Educational Resource Centre A thesis submitted to the Postgraduate School Ahmadu Bello University Zaria in partial fulfillment of the requirement for the degree of Master of Library Science Zaria 